\title{
A VIVÊNCIA NA RESIDÊNCIA PEDAGÓGICA EM QUÍMICA: ASPECTOS FORMATIVOS E REFLEXÕES PARA O DESENVOLVIMENTO DA PRÁTICA DOCENTE
}

\author{
Flávia Cristina Gomes Catunda de VASCONCELOS \\ Universidade Federal de Pernancuco \\ ORCID 0000-0003-1211-0728 \\ flavia.catunda@ufpe.br \\ João Roberto Ratis Tenório da SILVA \\ ORCID 0000-0001-9682-8889 \\ Universidade Federal de Pernambuco - CAA-UFPE \\ Caruaru, PE-Brasil \\ joao.ratis@ufpe.br
}

\begin{abstract}
RESUMO: O Programa da Residência Pedagógica é apresentado como um projeto inovador que estimula a articulação entre teoria e prática nos cursos de licenciatura. Além dediscutir a busca de melhorias na prática formativa do licenciando, esta pesquisa apresenta as percepções de licenciandos em Química que participaram do primeiro edital da CAPES, edital N. 8/2018 do campus do Agreste da Universidade Federal de Pernambuco. Mediante os dados apresentados, os residentes conseguiram desenvolver habilidades que versam na prática docente, atendendo aos objetivos do programa, em uma perspectiva de um futuro profissional que reflete a sua prática. Ademais, também foi percebido a necessidade de momentos formativos para os professores preceptores, bem como de uma melhor atuação da gestão escolar na receptividade do programa.
\end{abstract}

PALAVRAS-CHAVE: Autonomia. formação de professores. residência pedagógica.

\section{EXPERIENCE IN PEDAGOGICAL RESIDENCE IN CHEMISTRY: FORMATIVE ASPECTS AND REFLECTIONS FOR THE DEVELOPMENT OF TEACHING PRACTICE}

\begin{abstract}
The Pedagogical Residency Program is presented as an innovative project that stimulates the articulation between theory and practice in undergraduate courses in the country. In addition to discuss theseeking ofimprovements in the licensee's training practice, this research presents the perceptions of undergraduate Chemistry students who participated in the first call for proposals CAPES N. 8/2018 at Federal University of Pernambuco - campus do Agreste. Through the data presented, the resident graduates were able to develop skills that relate to teaching practice, meeting the objectives of the program, in a
\end{abstract}


perspective of a professional future that reflects their practice. In addition, it was also perceived the need for training moments for the teacher teachers, as well as a better performance of the school management in the receptivity of the program.

KEYWORDS: Autonomy. teacher training. pedagogical residence.

\section{EXPERIENCIA EN RESIDENCIA PEDAGÓGICA EN QUÍMICA: ASPECTOS FORMATIVOS Y REFLEXIONES PARA EL DESARROLLO DE LA PRÁCTICA DOCENTE}

RESUMEN: El Programa de Residencia Pedagógica se presenta como un proyecto innovador que estimula la articulación entre teoría y práctica en las carreras de grado en el país.Además de discutir la busca por mejoras en la práctica formativa del licenciatario, esta investigación presenta las percepciones de los estudiantes de licenciatura de Química que participaron en la primera convocatoria de propuestas CAPES N. 8/2018 nell'Universidad Federal de Pernambuco - campus do Agreste. A través de los datos presentados, los egresados residentes pudieron desarrollar competencias que se relacionan con la práctica docente, cumpliendo los objetivos del programa, en una perspectiva de futuro profesional que refleje su práctica. Además, también se percibió la necesidad de momentos de formación para los docentes da escuela, así como un mejor desempeño de la gestión escolar en la receptividad del programa.

PALABRAS-CLAVE: Autonomía. formación de profesores. residencia pedagógica. 


\section{Introdução}

O Programa da Residência Pedagógica (RP) surgiu mediante as ações previstas na Política Nacional de Formação dos Profissionais da Educação Básica, instituída pelo Decreto 8.752/2016, em consonância ao Plano Nacional de Educação (PNE), aprovado pela Lei n. 13.005/2014. Ambas viabilizam a colaboração entre os sistemas de ensino da educação básica e superior, contando com o um acordo de cooperação técnica através da Coordenação de Aperfeiçoamento de Pessoal de Nível Superior (CAPES), aprimorando a formação inicial e continuada de professores em todo o país(CAPES, 2018).

De modo complementar às ações desenvolvidas pelo Programa Institucional de Bolsas de Iniciação à Docência (Pibid), todos os participantes envolvidos neste processo podem desenvolverhabilidades e competências que possibilitam uma formação docente in loco. Ou seja, o licenciando tem a oportunidade de vivenciar as práticas de ensino ainda estudando, e o professor que está inserido na escola conseguiria aperfeiçoar sua prática, sem necessariamente estar em uma formação continuada.

Tanto o Pibid quanto a RP, ampliam as oportunidades de aplicação das discussões teórico-metodológicas sobre os processos de ensino e aprendizagem dos diversos conceitos e estratégias de ensino vistos na universidade, aplicando-os no ambiente escolar. Estes programas complementam as ações desenvolvidas no Estágio Supervisionado (ES) que é uma atividade curricular, obrigatória e garantida pela Lei de Diretrizes e Base (LDB) No 9394/96, que prepara o licenciando para o desenvolvimento da prática docente. O ES obrigatóriotambém tem horas destinadas a observação, planejamento, orientação e realização de atividades avaliativas na escola (BRASIL, 1996).

Para os licenciandos que não participam do Pibid e da RP, o ES obrigatório pode ser a única experiência realizada em um ambiente escolar, durante a sua graduação. Assim, identifica-se que ambos os programas são importantes, válidos e necessários para se melhorar o processo formativo dos futuros professores no país, além de viabilizar o desenvolvimento não só da identidade docente, mas a criação e aplicação dos recursos didáticos e das metodologias de ensino.

Nesta perspectiva, este manuscrito tem como objetivo analisar as reflexões de licenciandos em Química de uma IES no estado de Pernambuco que participaram da residência Pedagógica 2018-2020, identificando aspectos relevantes para a sua formação docente, contribuindo para a constituição de um profissional que reflete a sua prática.

\section{Pressupostos da Formação Docente em Química na perspectiva da prática reflexiva para o desenvolvimento da autonomia do professor}

A 'prática reflexiva' consiste, também, no exercício de possibilitar aos professores que eles se tornem meIhores naquilo que fazem ao longo de sua carreira profissional (ZEICHNER, 2008, p. 539).Segundo Kemmis e Wilkinson (2011), a reflexão deve ser conduzida para a ação e o significado desta estar relacionado a um contexto, pois apenas a reflexão não é suficiente para modificar o ambiente escolar, ela precisa estar associada a uma equipe de colaboração, compondo uma forma de enriquecer a reflexão individual.

Considerando as experiências desenvolvidas durante a RP, é possível desenvolver a prática reflexiva, viabilizando melhorias tanto na formação docente, quanto na realização das atividades desenvolvidas na escola. Ainda assim, possibilita colocar e discutir questões que resultam da prática, promovendo a construção de novos conhecimentos e estratégias diante das necessidades que Ihes são impostas. Segundo Zeichner 
(2008), os professores devem ir além dos limites da sala de aula, considerando aspectos de cunho social e político, sendo necessário que eles sejam mais atuantes na tomada de decisões da escola, na estruturação do currículo, no ensino, dentre outros.

Por certo período, a formação de professores era vista como um treinamento para a realização de atividades estruturadas, em que os docentes não refletiam sobre o porquê e para que se ensinar determinado conteúdo. Esta mudança de paradigma acontece quando se questiona sobre os saberes docentes, e sobre a necessidade de entender as razões e racionalidades associadas com as diferentes práticas desenvolvidas pelos professores.

Segundo Maldaner (2000) é necessário identificar a importância de se compreender como os professores refletem suas práticas, projetando ações mais concernentes com as suas necessidades formativas e as dos estudantes. Isto ocasiona uma discussão prática sobre a inserção de professores e formadores no debate para o avanço na qualidade educativa nas escolas e instituições do ensino superior. Com o cenário de inclusão do Pibid e da RP, identificam-se avanços no diálogo entre o que é desenvolvido na Universidade e o que as escolas que recebem destes projetos de ensino.

Logo, quando o licenciando está inserido em um projeto de ensino, que articula a prática e a teoria, surgem reflexões que buscam melhorias da prática docente com um nível mais profundo de amadurecimento profissional, desenvolvendo sua autonomia (TARDIF, 2011).Com sua prática na educação básica e diante dos desafios do cotidiano, o professor muitas vezes se depara com a necessidade de retornar os estudos ou se envolver em atividades que possibilitem a melhoria do seu saber profissional. Para o exercício da docência, este profissional precisa de uma formação de alto nível, de natureza universitária, adquirindo assim o diploma (TARDIF, 2011). Diante de tantas exigências, uma problemática nesta área é o exercer da licenciatura perder o seu valor não apenas por disputas salariais e precariedade do trabalho escolar, mas também pelas exigências do ofício de ser professor, o que pode explicar a baixa procura de candidatos aos cursos de licenciatura e até da desistência de ingressantes no decorrer do curso, além da desvalorização deste profissional pela sociedade. Outro ponto que merece destaque, se refere ao tempo dedicado para o desenvolvimento de atividades práticas desenvolvidas no estágio curricular.

Ferreira, Martins e Gonçalves (2019) apresentam um retrospecto sobre a formalização do ES no Brasil, desde a década de 30 até a Resolução 02 do Conselho Nacional de Educação do Ministério da Educação, em 2002, a qual institui a carga horária dos cursos de licenciatura em 400 horas de estágio curricular supervisionado, a partir da segunda metade do curso (BRASIL, 2002). Além disso, os autores fazem uma crítica no que se refere ao aumento da carga horária de estágio, pois o licenciando tem que buscar uma escola que o aceite enquanto estagiário, e que abra espaço para o desenvolvimento de suas atividades. Contudo, considerando as cidades de interior que, em sua maioria, possuem poucas escolas estaduais e municipais, pode ocorrer um desestímulo, tornando o processo mais difícil para a realização de suas atividades (FERREIRA; MARTINS; GONÇALVES, 2019).

Assim, identifica-se a viabilidade de permanência da RP e suas atribuições no âmbito formativo discente, para desenvolvimento do futuro professor, visto que no edital $N^{\circ} 1 / 2020$ se prevê 414 horas de atividades, com duração de 18 meses e dividido em 3 módulos, compreendendo a ambientação, preparação das aulas e regência. Esta carga horária deve ser aproveitada com créditos no curso superior, mediante regulamentos da Instituição de Ensino Superior (IES) (CAPES, 2020). Além disto, como é uma atividade remunerada, isto pode ser um estímulopara a permanência do licenciando no projeto de ensino e para o desenvolvimento das atividades didático-pedagógicas na escola. 


\section{Percurso metodológico}

Esta pesquisa foi realizada com os licenciandos em Química que participaramdo Programa Residência Pedagógica do Curso de Química-Licenciatura do Campus do Agreste da Universidade Federal de Pernambuco. Ao todo, participaram do projeto 55 licenciandos em Química, os quais compuseramdois núcleos estruturantes (27 e 28), divididos em seis escolas (quatro estaduais, um instituto federal e uma escola municipal). Destes, 42 responderam ao questionário, e os demais não enviaram as respostas a tempo para a construção deste manuscrito, não comprometendo a análise dos dados e sua interpretação.

O questionário foi estruturado de forma on-line, disponibilizado na plataforma JotForm. Esta escolha foi devido a mesma permitir ampla divulgação via rede social e e-mail, e considerando o cenário vivido durante a pandemia, este método de divulgação da pesquisa, foi viável para a realização da coleta de dados para compor esta pesquisa.

As questões foram estruturadas, contendo questão abertas e fechadas que traçavam o perfil do licenciando e suas concepções referentes a se os objetivos do RP foram atendidos, sua vivência formativa e o desenvolvimento da prática docente. Os resultados gerados pela própria plataforma também possibilitaram uma análise dos dados na perspectiva quali e quantitativa.

Ademais, esta pesquisa é de natureza quali-qualitativa, de forma complementar (FLICK, 2009), focalizando aspectos diferentes, mas que convergem na apresentação dos dados sobre a mesma temática que se refere a vivência dos residentes na RP. A construção da análise dos dados foi de cunho descritivo exploratório (OLIVEIRA, 2010), buscando analisar os documentos que norteiam os núcleos que compõem os objetivos da $\mathrm{RP}$, cruzando com as informações apresentadas no questionário, as quais buscavam explicações dos diversos fatores que envolvem o programa.

No decorrer da análise dos dados, foram identificadas categorias de análises em algumas das questões apresentadas no questionário. Elas serão apresentadas nos resultados a seguir, com informações relevantes no que tange os aspectos formativos, perpassando pelo desenvolvimento da autonomia e reflexão para a prática docente.

Para nortear a construção dos resultados desta pesquisa, tomou-se como base os principais objetivos da RP, os quais versam no aperfeiçoamento da formação dos licenciandos, viabilizando a relação teoria e prática de forma ativa, fortalecendo, ampliando e consolidando a relação entre a IES e a escola (CAPES, 2018). Também foi analisado como a experiência realizada possibilitou o desenvolvimento da identidade docente, e seus aspectos formativos em uma perspectiva reflexiva.

Os residentes participantes desta pesquisa estavam compreendidos entre 21 e 41 anos, sendo 15 (37\%) licenciandoscursando o $8^{\circ}$ período, concluindo a graduação em conjunto com as atividades da RP. Isto é um aspecto positivo, visto que um dos objetivos da RP é de incentivar atuação dos licenciandos na escola.

\section{Resultados e discussões}

No questionário foram apresentados seis grupos de afirmativas, para que os estudantes escolhessem, em livre demanda, conforme os seguintes grupos: Objetivos Atendidos na RP (7 afirmativas); Critérios de Prioridade (5 afirmativas); Desenvolvimento de Habilidades (10 afirmativas); Dificuldades encontradas na RP 
(10 afirmativas); Aspectos de melhorias da atividade do residente (6 afirmativas) e Melhorias para o 'sucesso' da RP (4 afirmativas). Também foi solicitado: “Explique como a RP ajudou você a desenvolver as habilidades marcadas acima" e "Escreva de forma sucinta, quais as suas percepções quanto a didática e as metodologias desenvolvidas pelo professor preceptor na escola. Quais os aspectos que precisariam ser usados como referência e poderiam ser aperfeiçoados?", conforme são apresentadas a seguir.

Considerando que a escolha das afirmativas era múltipla, os estudantes poderiam selecionar mais de uma afirmativa. O primeiro bloco, se referiu aos objetivos desenvolvidos durante o período de realização das atividades na RP, mediante os objetivos propostos no edital Nº 6/2018 (CAPES, 2018).

\section{Figura 1. QUANTITATIVO DE OBJETIVOS DESENVOLVIDOS PELOS RESISDENTES NA RP QUÍMICA-CA-UFPE}

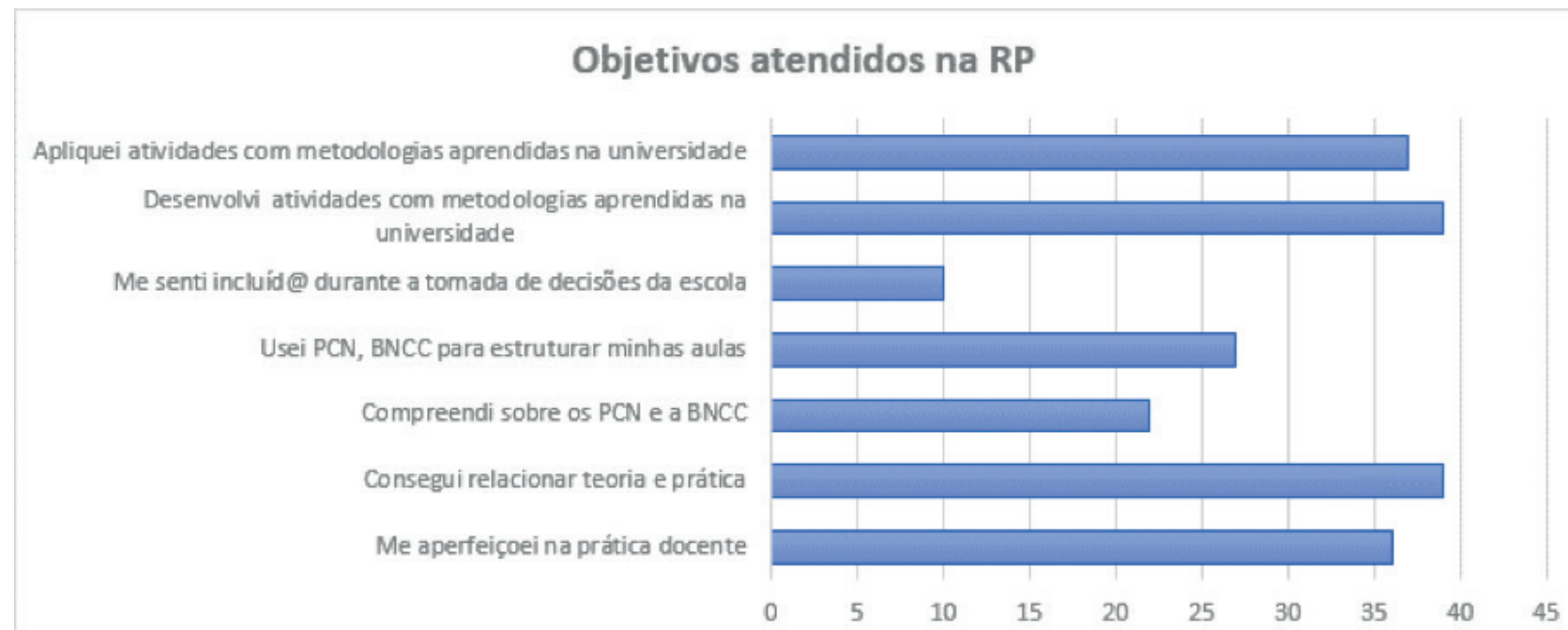

Fonte: os autores.

As afirmações que tiveram maior escolha pelos residentes atendem aos principais objetivos do Edital $\mathrm{N}^{\circ}$ 6/2018 da CAPES, identificando-se assim, que no cenário desta pesquisa, os aspectos previstos no edital foram atendidos, como por exemplo, a relação entre a teoria e prática, identificadas na primeira e segunda afirmativa da figura 1, com 39 e 37 residentes, respectivamente.Contudo, percebe-se que 10 estudantes afirmaram "não se sentirem incluídos durante a tomada de decisão da escola", sendo considerando um aspecto desfavorável para o desenvolvimento do licenciando, no que tange a contribuição dele na gestão escolar, visto que, de modo geral, os professores são os responsáveis pela inclusão e estruturação de um currículo mais democrático, que fazem a escola e produzem conhecimentos a partir de suas experiências (MALDANER; FRISON, 2014). Mesmo que os residentes não pudessem atuar com voz ativa na tomada de decisões, sua participação poderia ser como ouvinte, para compreender os aspectos de estruturação das atividades gestoras na escola.

Outro indicativo de que é preciso melhorar a nível discursivo e de compreensão, se refere a compreensão do que são os documentos oficiais (PCN e BNCC, por exemplo) que permeiam o processo de ensino e aprendizagem. Foi observado queapenas 22 licenciandos informaram que compreenderam estes documentos e 27 usaram os mesmos para a estruturação de suas aulas. Embora haja críticas ao modelo apresentado na BNCC (LEAL; BORGES; RIBEIRO, 2019), este documento é utilizado nas escolas públicas de esfera municipal e estadual, na estruturação de seus currículos, sendo então emergente a necessidade de se compreender seus aspectos formativos referentes ao processo de ensino e aprendizagem. 
No que se refere aos aspectos prioritários para a participação dos estudantes, de modo unânime, todos os residentes informaram que o principal era o desenvolvimento de experiência em sala de aula. Em relação ao aspecto financeiro, 24 licenciandos informaram ter média prioridade. Já 10 licenciandos declararam alta prioridade, sendo o mais 'flutuante' nos critérios de prioridade de escolha (figura 2).

\section{Figura 2. CRITÉRIOS DE PRIORIDADE PARA ATUAÇÃO DOS RESISDENTES NA RP QUÍMICA-CAA-UFPE}

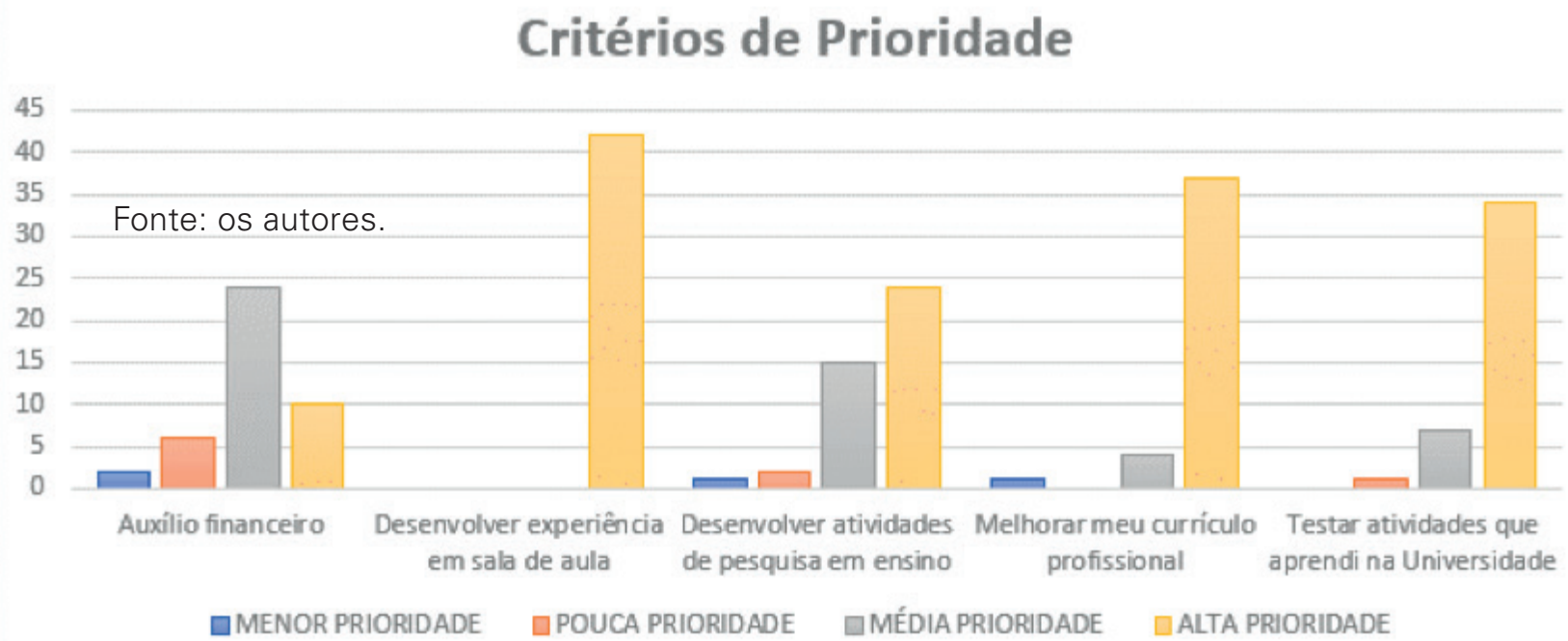

Com exceção da primeira afirmativa, as demais também estão coerentes com os objetivos da RP eos licenciandos também tiveram como prioritário o desenvolvimento de sua formação prática docente. Assim, continuando com as análises, foram estruturadas 10 afirmativas, para que os licenciandos escolhessem no mínimo 5 referentes ao desenvolvimento de suas habilidades no ser professor (Figura 3).

Figura 3. HABILIDADES DESENVOLVIDAS NA RP QUÍMICA-CAA-UFPE

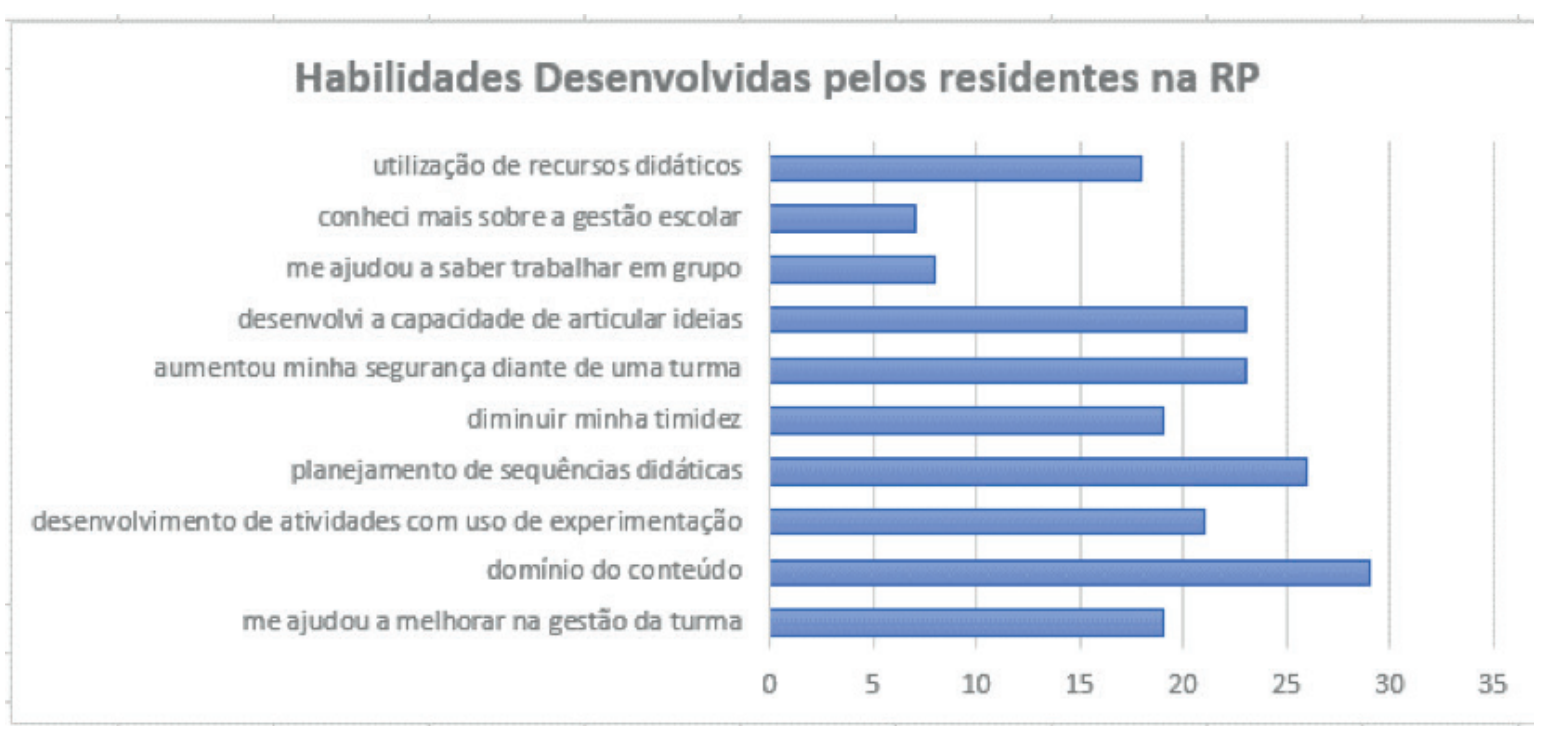

Fonte: os autores. 
Em consonância com as informações apresentadas na figura 1, apenas sete licenciandos informaram que conheceram mais sobre a gestão escolar. Mais adiante resgataremos esta informação, visto que ela também aparece como um aspecto preocupante no que tange a relação da atuação da gestão com o programada da RP. No que se refere os pontos altos, as principais habilidades desenvolvidas versaram no 'Domínio de Conteúdo - 29 licenciandos'; 'Planejamento de Sequências didáticas - 26 licenciandos'; 'Maior segurança diante a turma' e 'Desenvolvi a capacidade de articular ideias' ambas com 23 licenciandos. Estes aspectos foram ilustrados, quando questionados aos discentes o que ajudou os mesmos a desenvolverem tais habilidades, conforme é apresentado em alguns relatos, os quais versaram em quatro critérios de análises: Autonomia, RelaçãoTeoria-Prática, Reflexão e Estágio Supervisionado. Em relação a 'Autonomia', os discentes informaram que:

"Por meio do projeto tive uma maior autonomia na sala de aula, podendo desenvolver o que estava sendo discutido na Universidade. Além disso, pude participar e contribuir com diversos âmbitos da escola (gestão, coordenação, sala de aula...), pois o projeto possibilita essa inserção." H.M., 23 anos.

"A RP nos proporcionou momentos de autonomia dentro e fora da sala de aula. Através do planejamento, por exemplo, sempre buscava o uso de metodologias em que pudesse haver uma participação ativa dos estudantes." G.S., 22 anos.

"A RP nos concedeu uma autonomia em sala de aula que foi muito importante pra o desenvolvimento das habilidades docentes. Apesar de estarmos sempre sob supervisão, tínhamos autonomia suficiente pra fazer planejamentos e tomar decisões que contribuíram pra uma melhor gestão da turma, do tempo, das ideias e atividades."L.Z.., 22 anos.

Nestes registros, pressupõem-se que os licenciandos compreendem o processo de estruturação e realização de suas aulas, e que eles são sujeitos autônomos para fazer a sua escolha. Este é um caminho que viabiliza uma possível mudança no panorama atual no que tange os professores que apenas transmitem informações.

Em relação a 'Relação Teoria-Prática', são analisadas estas afirmações com os aspectos da autonomia, visto que é possível desenvolvê-la, quando o sujeito-professor reorganiza as suas atividades, escolhendo seus recursos e o que é melhor a ser utilizado no contexto escolar ao qual se está inserido.

"A RP me ajudou a resolver essas competências no exercício da prática quando pude conciliar a teoria aprendida na Universidade com a vivência das situações em sala de aula. Uma vez que a imersão possibilitou um maior desenvolvimento das atividades e avaliações estudadas." E.N., 27 anos.

"Na universidade aprendemos muito a teoria de tudo, sobre situações hipotéticas que podem acontecer, sobre didáticas utilizadas em diferentes turmas. No entanto, ao estarmos de frente a uma turma real, inseguranças podem ocorrer, e esse contato inicial com a docência nos ajuda e nos desafia a enfrentar e a testar diferentes metodologias e práticas que venham a ser úteis na nossa carreira." W.M., 22 anos.

"A participação no RP possibilitou o estreitamento do vínculo entre universidade e educação básica. Diante disso, era sempre objetivo de minhas ações levarpra escola o que havia aprendido na universidade. Refletir sobre o uso de metodologias englobou trabalhar nas habilidades de: usar experimentação, dominar o conteúdo, planejar sequências didáticas, analisar os recursos didáticos disponíveis na escola etc. Conforme se analisava o que a escola poderia me oferecer para realizar minhas ações, eu também conhecia um pouco sobre a gestão escolar." M.M., 25 anos. 
Analisando as respostas, identifica-se a preocupação dos licenciandos em relacionar o que estudam na IES com a o desenvolvimento de ações práticas no ambiente escolar. A RP possibilita que estas estratégias possam ser validadas ou não. Mesmo assim, a experiência é válida, considerando que os licenciandos estão em formação e precisam relacionar o contexto teoria e prática, bem como refletir esta prática.Conforme analisado por Silva e Martins (2019), a RP direciona o licenciando a relacionar a teoria com a prática, aplicando em sala as metodologias aprendidas de forma teórica nos cursos de licenciatura. Mesmo assim, reforça-se que o modelo de formação de professores não pode estar centrado na aquisição de conhecimentos e na técnica de 'como ensinar', mas, como processo de reflexão, visando o conhecimento profissional, necessário à ação docente. Ademais, conforme descreve Kemmis e Wilkinson (2011), a reflexão deve ser conduzida para a ação, modificando a práticaem sala de aula pelos licenciandos.

O terceiro critério de análise referente ao desenvolvimento de habilidades dos licenciandos, se refere a Reflexão. A resposta da discente M.M., apresentada anteriormente, tem elementos que configuram o processo de reflexão, pois ela considera o cenário que está inserida e assim reflete sobre qual 'melhor' estratégia para ser desenvolvida no momento de aula. Outras respostas, podem ser ilustradas a seguir:

"[... para que o processo de ensino ocorra da melhor forma, é preciso um aprimoramento do docente para com as necessidades da sala. E este aprimoramento exige uma atualização da didática do professor; da gestão da turma; do domínio do que está ensinando; da experimentação $e$ as diversas outras necessidades igualmente importantes. As quais fui contemplado através do Residência Pedagógica." A.J., 22 anos.

"Durante minha participação no RP, como proposta de desenvolvimento e realização de aulas, percebi que habilidades como o domínio de conteúdo foram perceptiveis, uma vez que a necessidade imposta de se preparar e preparar as aulas com embasamento era necessário. Com esse domínio, apreparação das estratégias se tornaram facilitadas, em alguns casos, o que ajudava na realização da aula. [...]" R.A., 23 anos.

\footnotetext{
"Por atuar na área de ciências, existia conteúdos da Química e Biologia, nos de Biologia tive que realmente voltar a estudar para dominar o conteúdo e mediar as aulas para os estudantes, em relação a capacidade articulação de ideias e trabalho em grupo, foram desenvolvidas simultaneamente, pois como trabalhamos em três, ficou mais fácil de analisar a possibilidade das ideias dos três e chegar a um consenso de quais realmente poderiam ser aplicadas na escola, o trabalho em grupo realmente funcionou pois os três discentes eram comprometidos com o projeto. Pela articulação das aulas, também tínhamos momentos ímpar, que cada um trabalhava sozinho em uma aula, e os momentos em conjunto, e em todos estes, para a utilização de recursos didáticos, todos os membros eram consultados paradefinir quais estariam aptos a serem aplicados nas aulas, e quanto a isso, as aulas de Metodologia do Ensino de Química na IES ajudaram bastante a selecionar tanto as metodologias quanto os recursos. [...]." C.V. 23, anos.
}

Os discentes também apresentaram elementos que perpassam na prática reflexiva, para a escolha das atividades a serem desenvolvidas em sala de aula, analisando quais são suas influências e como eles podem desenvolver no profissional as reformulações necessárias para se ter resultados mais significativos no processo de ensino e aprendizagem.Mesmo assim, considerando que os licenciandos estão em caráter formativo, se faz necessária a presença constante do preceptor e professor orientador que viabilize os aspectos que perpassam na reflexão de sua práticadocente inicial.Como diz Zeichener (2008), a prática reflexiva envolve outros sujeitos, e o professor exerce "um papel ativo na formulação dos propósitos e finalidades de seu trabalho e de que devem assumir funções de liderança nas reformas escolares." (ZEICHNER, 2008, p.539). 
Por fim, no que se refere ao Estágio Supervisionado, destacamos as respostas de estudantes que passaram pelo ES obrigatórioe compararam as atividades desenvolvidas em ambas as ações, refletindo sobre as contribuições para a sua formação docente.Conforme vê-se a seguir:

"Através de todo conjunto que me colocava em prática na sala de aula. Por meio das regências, vive experiências únicas, as quais não tive oportunidade no estágio supervisionado." A.C., 26 anos.

"A residência pedagógica me proporcionou oportunidades para desenvolver e refletir sobre a minha prática. Experiência melhor que os estágios, tanto em relação as aulas, metodologias e tanto quanto as relações pessoais com os alunos." S.G., 22 anos.

Identifica-se que conforme presente no edital No 8/2018 da CAPES e a análise de Silva e Martins (2019), os estágios que ocorrem nos cursos de licenciaturas não 'estão bons', sendo necessário a reformulação e o aperfeiçoamento das atividades a serem desenvolvidas na parceria IES e escola. Esta relação precisa ser eficaz nos aspectos formativos e de mudança que desencadeiem reais mudanças nas disciplinas de estágio, sendoreforçadopelas afirmativas dos licenciandos.Para o desenvolvimento de uma prática mais eficaz, no decorrer do programa os residentes relatavam certas dificuldades para a realização de suas atividades. Tanto os aspectos que precisariam ser melhorados no Programa e na Escola foram organizados e apresentas no questionário, conforme identifica-se nas figuras 4 e 5.

\section{Figura 4. DIFICULDADES IDENTIFICADASPELOS RESIDENTES NA RP QUÍMICA-CAA-UFPE}

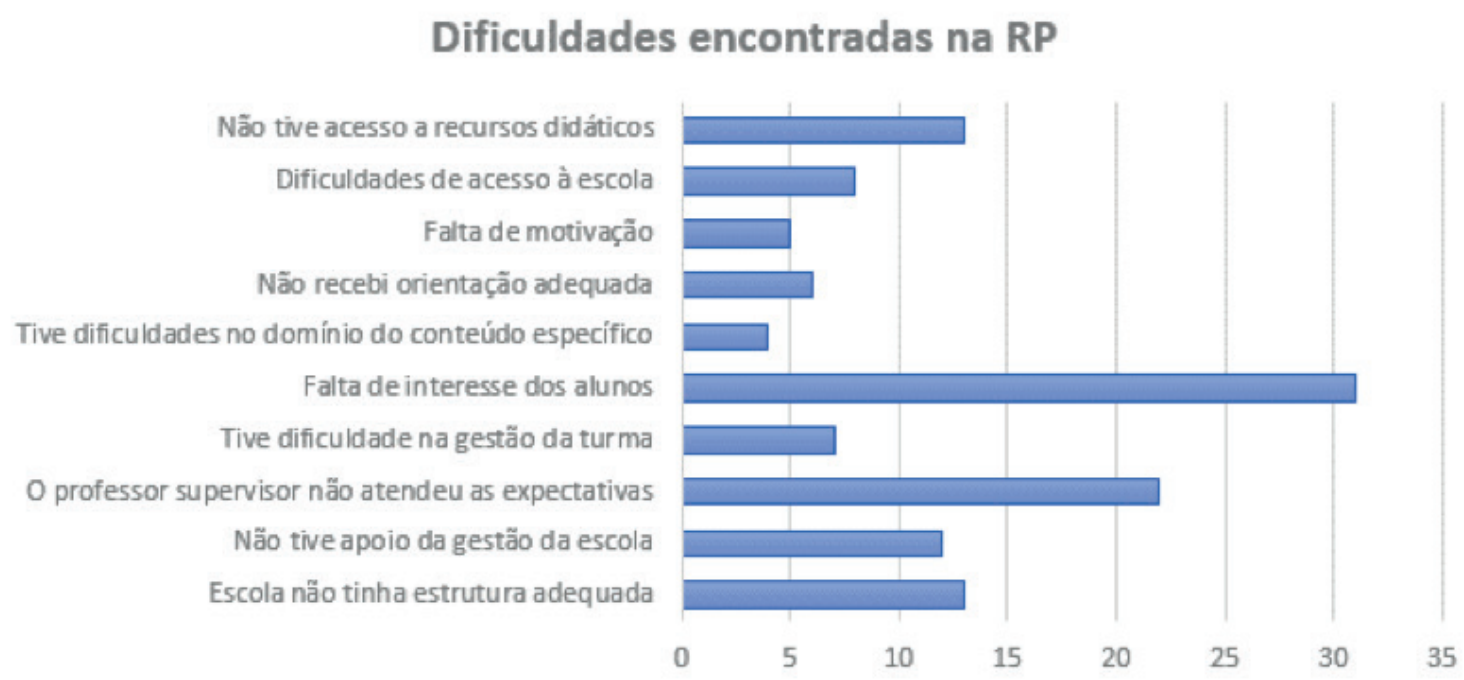

Fonte: os autores. 


\section{Figura 5. FALTAS IDENTIFICADAS NA RP QUÍMICA-CAA-UFPE}

\section{Itens que faltaram para o desenvolvimento das atividades na RP}

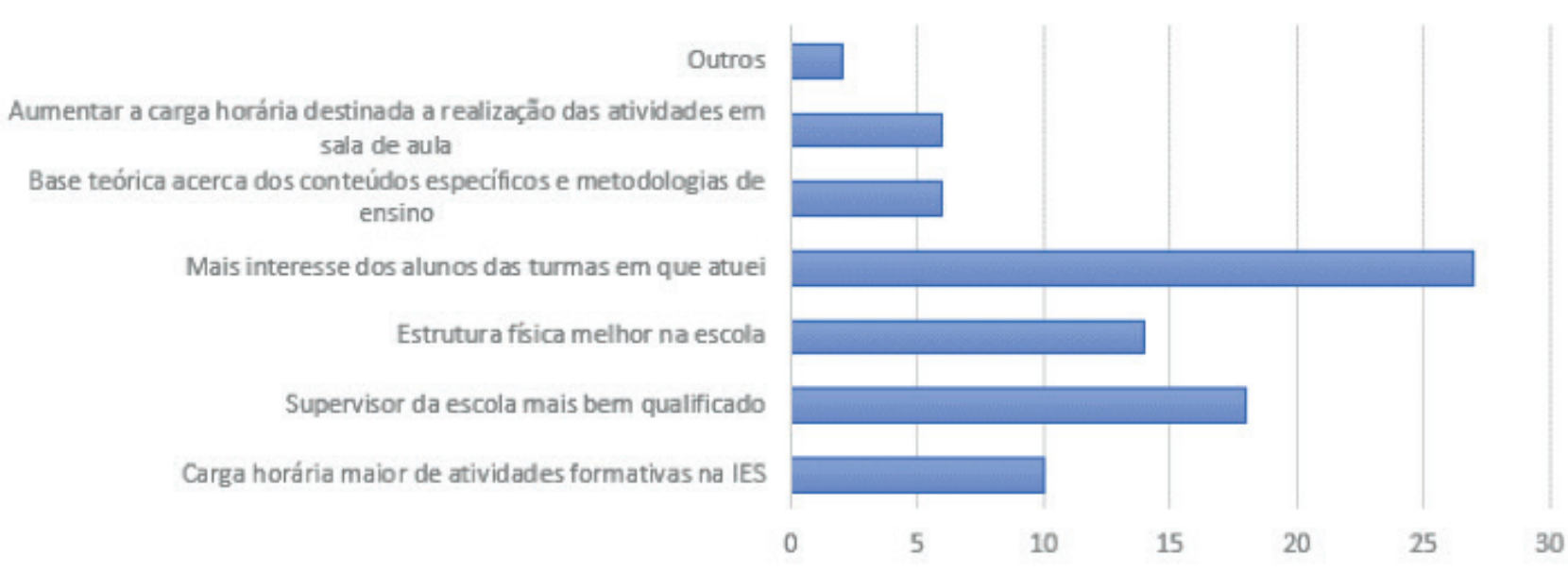

Fonte: os autores.

Nestas figuras percebe-se uma coerência nas respostas quanto a 'falta de interesse' por parte dos estudantes da escola (31 licenciandos - figura 4) e a necessidade de maior 'interesse dos estudantes' da escola (27 licenciandos - figura 5). Com esta inquietação, surge o questionamento de como ocorreram as aulas realizadas pelos residentes e se o esse desenvolvimento possibilitava a motivação dos estudantes nas aulas. Nesta perspectiva, identifica-se na literatura que quando ações que versam no acompanhamento psicológico dos estudantes, bem como a atuação de uma gestão escolar que os motivem e a compreenderem a importância do ambiente escolar para o seu desenvolvimento enquanto cidadão, pode-se motivar mais os estudantes (SIQUEIRA; WECHSLER, 2006; PEREIRAet al., 2019).

Ainda referente as duas figuras anteriores, 22 licenciandos (figura 4) e 18 licenciandos (figura 5) sinalizaram a necessidade de que o preceptor precisaria ser mais qualificado para as atividades docente. Mesmo sendo previsto em edital que ele precisa ser formado na área e ter no mínimo dois anos de experiência na atividade docente em Química, 14 licenciandos destacaram que os preceptores realizavam suas aulas em uma perspectiva mais tradicionalista, conforme é visto a seguir.

"O professor atuava como podia pela falta de motivação dos alunos e pela falta de recursos. Entretanto, a metodologia era com foco no tradicional, precisando equilibrar e alternar junto as metodologias ativas." V.F., 26 anos.

"O professor preceptor tinha formação em Química-Licenciatura, mas mestrado e doutorado em Engenharia Química, enquanto conteúdo ele era muito bom, tinha bom domínio do conteúdo de Química, de Biologia também, porque ele ensinou a vida toda Ciências, mas em questão de metodologia deixava a desejar, pois não fazia atividade pautadas em metodologias ativas de maneira alguma, nem experimentação, nem júri simulado, nem realidade virtual, nem sala de aula invertida, nada. Quanto a didática, era tradicionalista, dava aula no quadro, escrevia e explicava posteriormente, as vezes trazia uma aula em slides, porém os próprios estudantes nos falaram que não gostavam de aula em slide e preferia que fosse no diálogo e anotando as principais coisas.." C.O., 26 anos. 


\begin{abstract}
"O professor preceptor auxiliou como pode e tenho certeza que deu o melhor de si para ajudar os residentes. Entretanto, por ser alguém muito antigo na área da educação e não está atualizado nas novas metodologias, estranhava um pouco quando os residentes traziam coisas novas para as aulas, chegando a achar algumas vezes que os alunos não iam aprender da forma que os residentes traziam o conteúdo pra sala de aula. Isso era perceptível, porque algumas vezes, as aulas que eram ministradas pelos residentes, o professor preceptor, dava novamente, do jeito dele (tradicional)[...]." A.C., 23 anos

"O professor tinha uma metodologia muito tradicional, o que poderia ser feito era trabalhar com os professores a questão que iremos trabalhar novas metodologias e os benefícios que as mesmas podem atingir." L.E., 21 anos.
\end{abstract}

Considerando que para o desenvolvimento de aulas que versem nas metodologias ativas os professores precisam passar por um processo formativo, que geralmente é longo, destaca-se que essas mudanças não são fáceis de serem construídas, e que ocorrem de forma conjunta, possibilitando então a contribuição dos residentes também para os professores preceptores. Reforça-se que o professor em formação inicial ou continuada compreenda que sua atuação docente para o desenvolvimento da autonomia também passa nas ações que buscam a (re)estruturaçãodos conteúdos escolares, bem como na escolha das metodologias e recursos didáticos a serem utilizados em sala de aula.

Na figura 4, identifica-se que 13 residentes informaram tiveram dificuldades em ter acesso aos recursos didáticos, mas havia o suporte da universidade, para ter acesso a materiais de laboratório, além de dialogar com o professor orientador sobre o entendimento de algum conteúdo, bem como acesso e uso de recursos didáticos. Ademais, percebeu-se na RP, mais uma tarefa de se preparar profissionais que consigam desenvolver habilidades para adaptar os recursos disponíveis e buscarem meios que possibilitem esta ação, permeandosua autonomia (TARDIF, 2011).

Concomitante com este desenvolvimento, e conforme mencionado em outrora, a compreensão da gestão escolar e o seu funcionamento foi uma das habilidades não desenvolvidas pelos residentes. Além disso, na figura 4 identifica-se que 12 deles não tiveram apoio da gestão para o desenvolvimento das atividades. Destaca-se a resposta do licenciando G. A. que apresentou um pouco desta dificuldade:

"[...] Muitas atividades que queríamos fazer tínhamos que falar com a direção da escola, onde percebi que tudo que ocorre de atividades extras (fora ou dentro da escola) perpassa por um planejamento semestral e mesmo marcado às atividades não podia ser executada sem uma autorização e averiguação da equipe gestora se tinha disponibilidade naquele momento para realizar, a atividade burocrática realmente era muito burocrática. Sobre recuso didático aprendi a fazer meu próprio material sem esperar muito do material da escola, porém tudo que precisamos e a escola podendo oferecer eles nos deram." G.A., 25 anos.

Por mais resistente que seja, os responsáveis pela gestão escolar devem ter consciência de que os professores são os responsáveis pela inclusão e estruturação de um currículo mais democrático, que fazem a escola e produzem conhecimentos a partir de suas experiências (MALDANER; FRISON, 2014). Considerando que a RP também possibilita a troca imersiva de experiências por todos os sujeitos envolvidos, a gestão escolar deveria estar mais receptiva para as sugestões apresentadas pelos residentes.

Nesta perspectiva, o último ponto solicitado para os licenciandos se posicionarem, foi referente aos aspectos de melhorias para o 'Sucesso' da RP (Figura 6). 


\section{Figura 6. MELHORIAS PARA UM MELHOR DESENVOLVIMENTO NA RP QUÍMICA-CAA-UFPE}

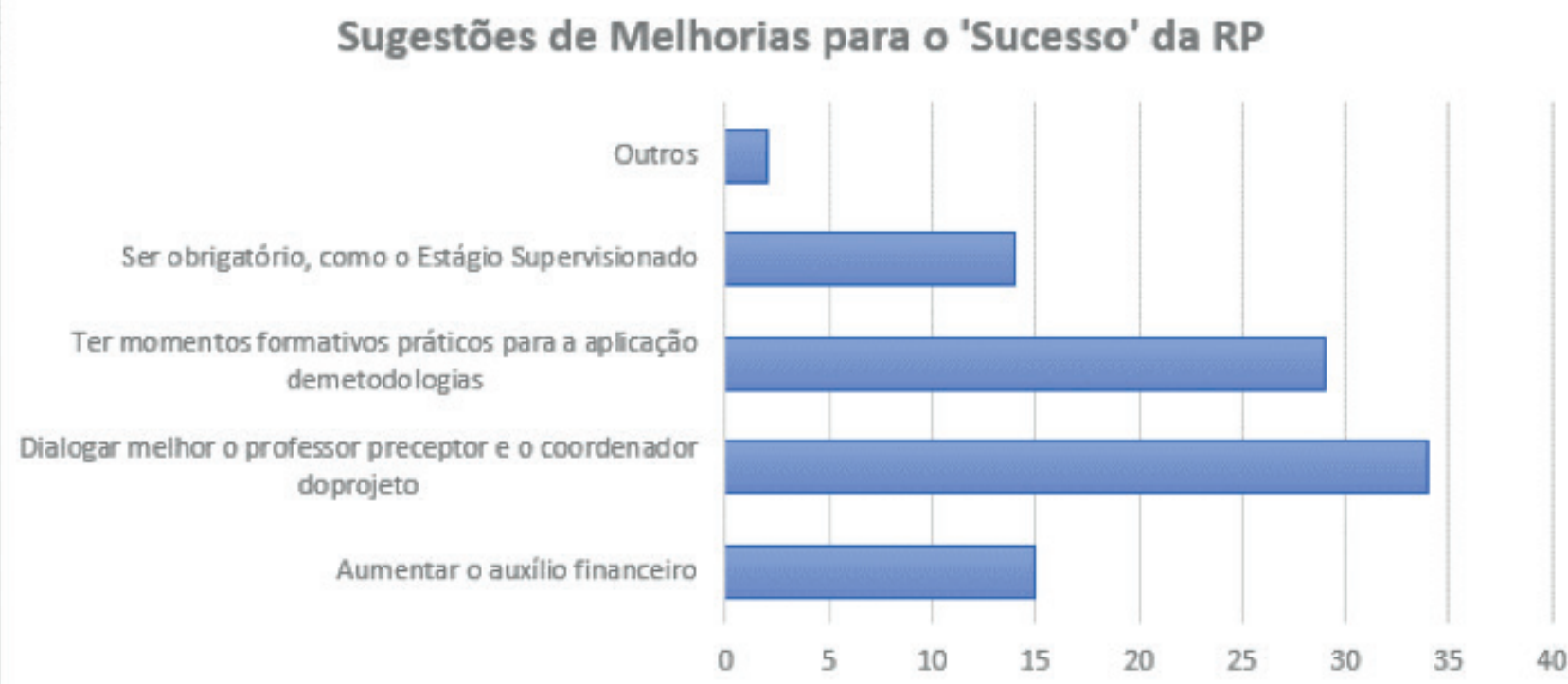

Fonte: os autores.

As principais afirmações escolhidas pelos residentes foram de o professor orientador dialogar mais com o professor preceptor (34 licenciandos) e ter mais momentos formativos para a aplicação de metodologias (29 licenciandos). Esta última vai de acordo com a afirmação 'carga horária maior para atividades formativas' (Figura 5 - 10 licenciandos).Além destas, 15 licenciandos informaram que era preciso aumentar o auxílio financeiro, e 14 a RP deveria ser obrigatória como o Estágio Supervisionado. Estando isso, coerente com o objetivo de se aprofundar a reflexão sobre a formação docente, contribuindo na valorização da profissão, bem como a carreira docente, no edital N. 8/2020 (CAPES, 2020). Contudo, Silva e Martins (2019) identificam que omodelo para a prática docente no ES, não está bom sendo necessária a mudança, e assim, o RP pode apresentar indicativos reais de reformulação nos ESdos cursos de licenciatura.

\section{Considerações finais}

A estruturação da RP desenvolvida no CAA-UFPE consistiu na perspectiva de possibilitar aos residentes momentos que eles pudessem desenvolver a autonomia, a prática reflexiva, e o desenvolvimento de habilidades que tangem a estruturação de suas aulas e o uso de recursos didáticos diversos. Para isto, a atuação deles na sala de aula, possibilitou a familiarização da realidade escolar e, consequentemente, vivenciar os hábitos rotineiros deste espaço. Logo, os licenciandos compreenderam que as mudanças necessárias que a escola precisa ter requer envolvimento, com interações que acontecem entre gestores, professores e até os próprios alunos (KEMMIS; WILKINSON, 2011).

A estratégia utilizada durante os encontros presenciais entre o professor orientador e os residentes, viabilizou o desenvolvimento de uma prática reflexiva, possibilitando que eles desenvolvessem o hábito de revisitar os planejamentos e estratégias traçadas para a sala de aula. Demonstrando assim, o amadurecimento e compreensão que a prática docente não se restringe ao domínio do conteúdo, mas também na escolha das metodologias e atividades a serem realizadas em sala de aula. 
Mediante as informações apresentadas, identificou-se que a RP se demonstrou um processo formativo pertinente a ser continuado nos cursos de licenciatura, mas com a necessidade de uma maior atuação do professor orientador no que tange a realização de mais momentos formativos para os licenciandos, bem como aos professores preceptores. Visto que, os residentes afirmaram ter a necessidade desse maior diálogo, conforme apresentado na figura 6.Por fim, a pesquisa apresentada e as respostas e relatos dos licenciandos, mostrou que as atividades desenvolvidas na RP de Química, possibilitou avanços na formação dos jovens professores, vislumbrando-se assim a premissa de que eles serão bons profissionais ao exercerem a prática docente.

\section{AGRADECIMENTOS}

Agradecemos a todos os residentes participantes do primeiro edital da Residência Pedagógica do CAA-UFPE, a CAPES pelo acordo firmado com as IES e Ministério da Educação, o qual viabilizou o fomento do programa. Bem como a todos os professores, gestores e estudantes da educação básica que participaram destas ações.

\section{REFERÊNCIAS}

BRASIL. Lei de Diretrizes e Bases da Educação Nacional. Lei n 9.394, de 20 de dezembro de 1996. Disponível em: <http://portal.mec.gov.br/seesp/arquivos/pdf/lei9394_ldbn1.pdf> Acesso em: 28. set. 2020.

BRASIL. CNE/CP. Resolução CNE/CP 01/2002, de 18 de Fevereiro de 2002, Resolução CNE/CP 02/2002, de 19 de Fevereiro de 2002. Brasília/DF, 2002. Disponível em:<http://portal.mec.gov.br/seesp/arquivos/pdf/ res2_2.pdf>. Acesso em: 25 de set. 2020.

CAPES. Acordo de Cooperação Técnica N. 6/2018 da CAPES. Processo N. 23038.007085/2018-62. Disponível em: <https://capes.gov.br/images/stories/download/legislacao/08062018-ACT-ASSINADO-05-06-18.pdf> Acesso 24 set. 2020.

CAPES.Edital CAPES nº 01/2020. Programa de Residência Pedagógica. Disponível

em: <http://www.capes.gov.br/>. Acesso em 28 set. 2020.

FAZENDA, I. Integração e interdisciplinaridade no ensino brasileiro: efetividade ou ideologia? São Paulo: Loyola, 1979.

FERREIRA, M.; MARTINS, E.; GONÇALVES, K. O estágio supervisionado como espaço de reflexão sobre o exercício da docência em química no ensino médio. Form. Doc., Belo Horizonte, v. 11, n. 20, p. 11-26, jan./ abr. 2019. Disponível em <http://www.revformacaodocente.com.br>. Acesso: 28 set. 2020.

FLICK, U. Introdução a Pesquisa Qualitativa. 3 ed. Porto Alegre: Artmed, 2009.

KEMMIS, S.; WILKINSON. A pesquisa-ação participativa e o estudo da prática. IN: DINIZ-PEREIRA; ZEICHNER (Org.) A pesquisa na formação e o trabalho docente. 2 ed. Belo Horizonte: Autêntica Editora, 2011.

LEAL, S.M.; BORGES, M.C.; RIBEIRO, B.O.L. Discussão sobre formação de professores, inicial e continuada e a relação com a nova BNCC. Educação e Fronteiras On-Line. Dourados/MS, v.9, n.26 p.6-21, maio/ago. 2019. Disponível em: https://ojs.ufgd.edu.br/index.php/educacao/article/view/12771/6111 Acesso: 29 set. 2020 
MALDANER, O. A Formação inicial e continuada de professores de Química: professores/pesquisadores. 1 ed. Ijuí, RS: Ed. Unijuí, 2000.

MALDANER, O.A.; FRISON, M.D. Constituição do Conhecimento de Professor de Química em Tempos e Espaços Privilegiados na Licenciatura. In: NERY; MALDANER (Orgs.) Formação de professores: compreensões em novos programas e ações. ljuí: Ed. Unijuí, 2014, p.43-81.

OLIVEIRA, M. M. Como fazer pesquisa qualitativa. 3. Ed. Revista e ampliada. - Petrópolis - RJ: Vozes, 2010.

PEREIRA, M.D.; FONTES, T.A.; SILVA, G.G.I.; COSTA, C.F.T. Contribuições do psicólogo escolar em relação ao processo de motivação do aluno no contexto educacional. Anais do XX Congresso de Psicologia da Universidade Tiradentes (Unit). 2019. Disponível em: https://www.psicologia.pt/artigos/textos/A1335.pdf Acesso 30 set. 2020.

SIQUEIRA, G.G.;WECHSLER, S.M. Motivação para a aprendizagem escolar: possibilidade de medida. Avaliação Psicológica. Vol. 5, n. 1, junio, 2006, p. 21-31. Disponível em: https://www.redalyc.org/pdf/3350/335027179004. pdf Acesso: 30 set. 2020.

SILVA, M.C.; MARTINS, I.G.R. Representações sobre as relações teoria-prática e universidade-escola no Programa de Residência Pedagógica. Anais do XII Encontro Nacional de Pesquisa em Educação e Ciências (XII ENPEC). Universidade Federal do Rio Grande do Norte, Natal-RN, 2019. Disponível em: http://abrapecnet. org.br/enpec/xii-enpec/anais/resumos/1/R1618-1.pdf Acesso: 30 set. 2020.

TARDIF, M. Saberes docentes e formação profissional. Petrópolis, RJ: Vozes, 2011

ZEICHNER, K.M. Uma Análise Crítica sobre a "Reflexão" como Conceito Estruturante na Formação Docente. Educação \& Sociedade. Campinas: CEDES, v. 29, 2008, p.535-554.

ZEICHNER, K. M.; LISTON, D. P. Reflectiveteaching: Anintroduction.Mahwah, NJ: Erlbaum,1996.

VASCONCELOS, F. C. G. C.; SILVA, J. R. R. T.; A vivência na residência pedagógica em química: aspectos formativos e reflexões para o desenvolvimento da prática docente Formação Docente - Revista Brasileira de Pesquisa sobre Formação de Professores. Belo Horizonte. Vol. 13, n. 25 (p. 219-234) 31 dez. 2020. ISSN:2176-4360. DOI https:// doi.org/10.31639/rbpfp.v13i25.426 
